\title{
SAMONIKLO LJEKOVITO, AROMATIČNO I MEDONOSNO BILJE LIVADA JUGOISTOČNOG DIJELA SAMOBORSKOG GORJA
}

\author{
WILD MEDICINAL, AROMATIC AND HONEY PLANT SPECIES \\ OF THE SOUTHEASTERN PART OF THE SAMOBORSKO GORJE
}

\section{Ljubičić, F. Vugrinčić, Dubravka Dujmović Purgar}

\section{SAŽETAK}

Jugoistočni dio Samoborskog gorja smješten je na krajnjem istočnom dijelu Parka prirode Žumberak-Samoborsko gorje, između gradova Samobora i Jastrebarskog. Najviši dijelovi ovog brdskog područja obrasli su gustom šumom, a ispod tog pojasa prevladavaju livade koje su u doticaju s obradivim površinama: njivama, voćnjacima i vinogradima. Cilj ovog rada bio je utvrditi florni sastav livada te izdvojiti i opisati ljekovite, aromatične i medonosne vrste. Terensko istraživanje provedeno je tijekom vegetacijske sezone 2010. na pet lokaliteta. Rezultati ukazuju na veliko bogatstvo biljnih vrsta s ljekovitim i aromatskim svojstvima, a istraživanjem je prikupljeno i determinirano ukupno 88 svojti od kojih 59 vrsta pripada skupini ljekovitih i aromatičnih biljaka. Posebna pozornost ukazana je ljekovitim biljnim vrstama koje su uvrštene u Hrvatsku farmakopeju. Njihove droge smatraju se oficijelnima i koriste se u službenoj medicini.

Ključne riječi: ljekovite biljke, aromatične biljke, livada, Samoborsko gorje, Hrvatska

\begin{abstract}
Plešivičko gorje (Plesivica hills) is located in the far eastern part of Žumberak-Samoborsko gorje Nature Park, near the towns of Samobor and Jastrebarsko. The highest parts of this hill area are wooded, and beneath this area there are meadows which are close to arable land - fields, orchards and vineyards. The aim of this study was to determine the flora of meadows in Plešivica hills and to isolate and describe medicinal, aromatic and honey plants. Field research was carried out during 2010 vegetation season in five different locations. Results reflect the wealth of plants with medicinal and aromatic properties, and in the research a total of 88 species were collected and determined of which 59 species belong to a group of medicinal and aromatic plants. Special attention was given to
\end{abstract}


I. Ljubičić i sur.: Samoniklo ljekovito, aromatično i medonosno bilje livada jugoistočnog dijela Samoborskog gorja

medicinal plants included in Croatian Pharmacopoeia. They are considered official and are used in "official" medicine.

Key words: medicinal plants, aromatic plants, meadow, Samobor hills, Croatia

\section{UVOD}

Jugoistočni dio Samoborskog gorja kao dio Parka prirode ŽumberakSamoborsko gorje, zapravo je oko $5 \mathrm{~km}$ dugačak hrbat koji svojom sjevernom stranom nadvisuje kraj Rudarske drage, a na jugu i jugoistoku strmo se uzdiže nad jaskanskim pribrežjem. Mnogobrojni izvori i vodotoci čine ovo područje izrazito bogato vodom što u konačnici utječe i na brojnost i raznolikost biljnog svijeta (Kovačević i sur., 1971.).

Klimatološki gledano, karakterističan položaj Samoborskog gorja uvjetovao je da su u ovom podneblju osim prevladavajućih kontinentalnih utjecaja, primjetni i oni mediteranski, a osjeća se i utjecaj Panonske nizine, Alpa i Dinarida. Prevladava umjereno topla klima bez suhog razdoblja (Dujmović, 2007.). Srednja godišnja temperatura (2006. - 2010.) iznosi $9,1^{\circ} \mathrm{C}$, a količina oborina 1261,0 mm (Penzar i Penzar, 1989.).

Bogatstvo i raznolikost vegetacije uvjetovano je, između ostalog i smještajem ovog brdskog kraja na tzv. prijelaznom području na kojem se susreću i isprepliću elementi flore različitih regija u biljno-geografskom smislu (Forenbacher, 1995.).

Glede raznolikosti, rasprostranjenosti i raščlanjenosti biljnog pokrova ovog područja najznačajnija su dva ekosustava: šume i travnjaci. Šume pokrivaju oko $2 / 3$ površine dok ostali dio većinom čine travnjaci: livade-košanice i pašnjaci. Uz ova dva dominantna ekosustava nalazimo još i mnoštvo drugih. Na iskrčenim površinama i napuštenim pašnjacima, na kiselim tlima, razvile su se šikare $\mathrm{i}$ šumarci te raslinstvo vriština i bujadnica. Travnjaci ovog područja većinom su nastali djelovanjem čovjeka, odnosno krčenjem šuma. Prevladavaju livade-košanice koje se održavaju košnjom, najčešće jednom godišnje, dok su pašnjaci vrlo rijetki. Od nekoliko livadnih zajednica, na istraživanom području najvažnija je i najraširenija zajednica uspravnog ovsika i srednjeg trpuca (As. Bromo-Plantaginetum mediae $\mathrm{Ht}$ (1931.) 1949.). Javlja se na suhim i vrlo plitkim tlima (rendzine, rijeđe smeđa tla), bogatima humusom i neutralne $\mathrm{pH}$ vrijednosti. $\mathrm{U}$ Samoborskom gorju značajne su još i livadna zajednica kalničke šašike (As. Seslerietum kalnikensis Ht. 1942.), zajednica uspravnog ovsika i jednoklasne šiljke (As. Bromo erecto-Danthonietum calycinae Šugar 1973.) te zajednica trave tvrdače (As. Arnico-Nardetum Ht. (1930) in Horvat et. al. 1974) (Trinajstić, 2008.). 
I. Ljubičić i sur.: Samoniklo ljekovito, aromatično i medonosno bilje livada jugoistočnog dijela Samoborskog gorja

U ljekovito bilje ubrajaju se one biljne vrste čiji jedan ili više dijelova sadrže biološki aktivnu tvar koja se može iskoristiti u terapijske svrhe ili za kemijskofarmaceutske sinteze. U aromatično bilje ubrajamo one vrste koje sadrže jednu ili više aktivnih tvari posebnog mirisa ili okusa koje se iskorištavaju za spravljanje mirisa, kozmetičkih proizvoda, napitaka i aroma za živežne namirnice. Stroga podjela između ove dvije grupe ne postoji jer neke se vrste mogu koristiti i u medicinske svrhe i za dobivanje arome pa u praksi često obje skupine zovemo zajedničkim imenom ljekovito bilje (Grdinić i Kremer, 2009.).

Kao što se i iz same definicije vidi, za ljekovitost pojedine biljne vrste zaslužne su aktivne tvari koje one sadrže. Te aktivne tvari većinom su organske prirode i mogu se razvrstati u nekoliko većih skupina kao što su ugljikohidrati, organske kiseline, glikozidi, biljne masti, eterična ulja, alkaloidi i vitamini (Grdinić i Kremer, 2009.).

Aktivne (djelatne) tvari mogu se nalaziti samo u jednom dijelu biljke (ili su $\mathrm{u}$ tom dijelu u najvećoj koncentraciji) ili mogu biti ravnomjerno raspoređene $u$ nekoliko biljnih organa. S obzirom na to, u nekim slučajevima prikuplja se samo određeni dio biljke, npr. korijen, a u nekim cijeli nadzemni dio bez odrvenjelih dijelova - zelen (Galle Toplak, 2001.). Od tako prikupljenog biljnog materijala spravljat će se droge koje će se u obliku različitih pripravaka koristiti u fitoterapiji. Pojam biljna droga odnosi se na osušene i usitnjene (nekad i cijele ili narezane) biljke ili biljne dijelove koji sadrže određenu djelatnu tvar. Droge mogu biti oficijalne (službene) i neoficijalne. Velik broj biljnih vrsta ima dugu tradiciju primjene u narodnoj medicini (neke čak i od antičkog doba), no farmakološki učinak ili kemijski sastav njihovih droga još uvijek nije dovoljno istražen. Takve droge nazivaju se neoficijelne droge. S druge pak strane, nekim je drogama dokazano kliničko djelovanje, poznat je njihov kemijski sastav i točno određena (normirana) količina nekih aktivnih tvari koje moraju sadržavati. Takve droge nazivaju se oficijelne droge, a njihovi opisi nalaze se u farmakopejama (Kuštrak, 2005.).

\section{MATERIJALI I METODE}

Istraživanje je provedeno tijekom vegetacijskih sezona 2010. i 2011. godine, na odabranim lokalitetima livada jugoistočnog dijela Samoborskog gorja, a nalaze se od 400 do $600 \mathrm{~m} / \mathrm{nv}$ (Slika 1). 
I. Ljubičić i sur.: Samoniklo ljekovito, aromatično i medonosno bilje livada jugoistočnog dijela Samoborskog gorja

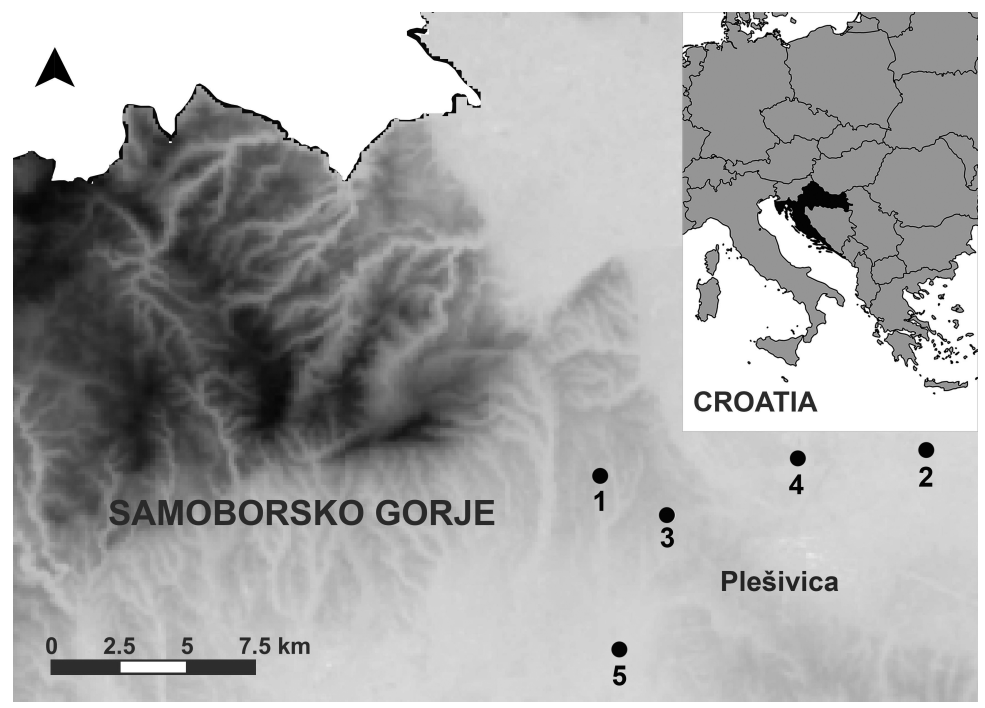

Slika 1. Geografski prikaz istraživanog područja s lokalitetima (1 - Prekrižje Plešivičko, 2 -iznad sela Kotari, 3 -između Prekrižja Plešivičkog i prijevoja Poljanice, 4 - Bukovje Podvrško, 5 - u blizini sela Jurjevčani)

Picture 1 The geographical position of investigated area with localities (1 - Prekrižje Plešivičko, 2 - above the village of Kotari, 3 - between Prekrižje Plešivičko and pass Poljanice, 4 - Bukovje Podvrško, 5-near the village of Jurjevčani)

Floristička istraživanja obuhvaćala su dvogodišnji rad na terenu $u$ vegetacijskom periodu od ožujka do mjeseca listopada. Terensko istraživanje podrazumijevalo je pronalazak, fotodokumentiranje i prikupljanje biljnog materijala koji je potom herbariziran i determiniran prema uobičajenim ključevima i ikonografijama: Hegi (1906. -1931.), Javorka i Csapody (1934.), Bonnier (1962.), Tutin i sur. (1964. - 1980., 1993.), Domac (1994.) i Knežević (2006.). Terenskim istraživanjem obuhvaćena je sveukupna livadna flora, a nakon determinacije prikupljenih svojti izrađeni su herbarijski primjerci pohranjeni pri Zavodu za botaniku Agronomskog fakulteta te izdvojene ljekovite i aromatične vrste i tablično obrađene. Biljne vrste, rodovi i porodice navedeni su u popisu flore abecednim redom unutar viših sistematskih kategorija, a nazivi svojti usklađeni su prema Nikoliću (2017.). Za svaku vrstu, uz naziv i taksonomsku pripadnost, navedeni su i podaci o životnom obliku, trajanju života, vremenu cvatnje i flornom elementu, a također posebno su označene medonosne biljne vrste i dio biljke koji se sabire. 
I. Ljubičić i sur.: Samoniklo ljekovito, aromatično i medonosno bilje livada jugoistočnog dijela Samoborskog gorja

Životni oblici određeni su prema Garckeu (1972.), a nadopunjeni podacima o lokalnoj flori prema Kovačeviću (1976.). Za životne oblike korištene su sljedeće kratice: $\mathrm{T}$ - Therophyta, $\mathrm{Ch}$ - Chamaephyta, $\mathrm{H}$ - Hemicryptophyta i $\mathrm{G}$ - Geophyta.

Trajanje života određeno je prema Garckeu (1972.) i Hulini (1991.). Za trajanje života biljaka korištene su sljedeće kratice: $\mathrm{j}$ - jednogodišnje, $\mathrm{d}$ - dvogodišnje, z.traj - zeljaste trajnice.

Fitogeografska analiza (florni elementi) usklađena je prema Garckeu (1972.). Za vrste koje nisu navedene unutar ove literature florni elementi određeni su prema podacima o lokalnoj flori iz radova Huline (1989., 1991.), Kovačevića (1976.), Šegulje (1977.), Vrbeke (2000.). Za florne elemente korištene su sljedeće kratice:

euras - euroazijski florni element

eur - europski florni element

sre - srednjeeuropski florni element

jue - južnoeuropski florni element

submed - submediteranski florni element

circ - biljke cirkumholartičke rasprostranjenosti

prealp - prealpski florni element

šir - biljke široke rasprostranjenosti

adv - adventivne vrste

Medonosne vrste usklađene su prema Kneževiću (2006.) i Šimiću (1980.), a označene su znakom + .

Za svaku ljekovitu i aromatičnu biljnu vrstu naveden je dio biljke koji se sakuplja i od kojeg se zatim spravlja biljna droga. Ljekovite i aromatične vrste određene su prema sljedećim autorima: Gelenčir i Gelenčir (1991.), Galle Toplak (2001.), Kuštrak (2005.), Hrvatska farmakopeja (2007.) te Grdinić i Kremer (2009.). Za dio biljke od kojeg se koristi/spravlja biljna droga, korištene su sljedeće oznake:

\begin{tabular}{|c|c|}
\hline \multicolumn{2}{|c|}{ Oznaka - dio biljke } \\
\hline$U_{\text {-zelen }}$ & - podanak \\
\hline$\nabla_{- \text {list }}$ & - lukovica \\
\hline -korijen & (1) - plod \\
\hline - cvijet & - gomolj \\
\hline
\end{tabular}


I. Ljubičić i sur.: Samoniklo ljekovito, aromatično i medonosno bilje livada jugoistočnog dijela Samoborskog gorja

Svi podaci prikazani su tablično, obrađeni te prikazani u obliku dijagrama. I na kraju, posebno su izdvojene i ukratko opisane (izgled, oficijelna droga, aktivna tvar, djelovanje i uporaba) one ljekovite vrste čije su biljne droge oficijelne, odnosno koje su opisane u Hrvatskoj farmakopeji.

\section{REZULTATI I RASPRAVA}

Istraživanjem je prikupljeno i determinirano ukupno 88 svojti. Analizom prikupljenog biljnog materijala ustanovljeno je 59 svojti koje pripadaju skupini ljekovitih i aromatičnih biljaka, a medonosna je 41 svojta (Tablica 1).

Tablica 1. Ljekovite, aromatične i medonosne vrste livada jugoistočnog dijela Samoborskog gorja (ŽO - životni oblik, TŽ - trajanje života, VC - vrijeme cvatnje, FE - florni element, M - medonosna vrsta, DB - dio biljke koji se sabire)

Table 1. Medicinal, aromatic and honey species of the southeastern part of the Samoborsko gorje (ŽO - life form, TŽ - life cycle, VC - time of flowering, FE - floral element, $M$ - honey plants, DB - a useful part of the plant)

\begin{tabular}{|c|c|c|c|c|c|c|c|}
\hline & SVOJTA & $\check{Z ̌ O}$ & $T \bar{Z}$ & $V C$ & $F E$ & $M$ & $D B$ \\
\hline 1 & $\begin{array}{l}\text { PTERIDOPHYTA } \\
\text { SPHENOPSIDA } \\
\text { EQUISETACEAE } \\
\text { Equisetum arvense L. }\end{array}$ & $\mathrm{G}$ & z.traj & $3-5$ & šir & & \\
\hline $\begin{array}{l}2 \\
3 \\
4\end{array}$ & $\begin{array}{l}\text { SPERMATOPHYTA } \\
\text { MAGNOLIOPSIDA } \\
\text { APIACEAE } \\
\text { Carum carvi } \mathrm{L} \text {. } \\
\text { Daucus carota } \mathrm{L} \text {. } \\
\text { Pastinaca sativa } \mathrm{L} \text {. }\end{array}$ & $\begin{array}{l}\mathrm{H} \\
\mathrm{H} \\
\mathrm{H}\end{array}$ & $\begin{array}{l}d \\
d \\
d\end{array}$ & $\begin{array}{l}4-7 \\
6-9 \\
7-8\end{array}$ & $\begin{array}{c}\text { prealp } \\
\text { euras } \\
\text { euras }\end{array}$ & $\begin{array}{l}+ \\
+ \\
+\end{array}$ & \\
\hline 5 & $\begin{array}{l}\text { ASCLEPIADACEAE } \\
\text { Vincetoxicum hirundinaria Medik. }\end{array}$ & $\mathrm{H}$ & z.traj & $5-9$ & euras & + & 0 \\
\hline $\begin{array}{c}6 \\
7 \\
8 \\
9 \\
10 \\
11 \\
12 \\
13 \\
14 \\
15 \\
16\end{array}$ & $\begin{array}{l}\text { ASTERACEAE } \\
\text { Achillea millefolium } \mathrm{L} . \\
\text { Artemisia vulgaris L. } \\
\text { Bellis perennis } \mathrm{L} . \\
\text { Carlina acaulis } \mathrm{L} . \\
\text { Centaurea cyanus } \mathrm{L} . \\
\text { Centaurea jacea } \mathrm{L} . \\
\text { Conyza canadensis (L.) Cronq. } \\
\text { Petasites hybridus } \text { (L.) G.M.Sch. } \\
\text { Solidago canadensis } \mathrm{L} . \\
\text { Tanacetum vulgare } \mathrm{L} . \\
\text { Tussilago farfara } \mathrm{L} .\end{array}$ & $\begin{array}{c}\mathrm{H} \\
\mathrm{H} \\
\mathrm{H} \\
\mathrm{H} \\
\mathrm{T} \\
\mathrm{H} \\
\mathrm{T} \\
\mathrm{G} \\
\mathrm{H} \\
\mathrm{H} \\
\mathrm{G}\end{array}$ & $\begin{array}{c}\text { z.traj } \\
\text { z.traj } \\
\text { z.traj } \\
\text { z.traj } \\
\text { j } \\
\text { z.traj } \\
\text { j } \\
\text { z.traj } \\
\text { z.traj } \\
\text { z.traj } \\
\text { z.traj }\end{array}$ & $\begin{array}{c}6-9 \\
7-9 \\
3-11 \\
7-9 \\
6-9 \\
6-10 \\
6-9 \\
3-5 \\
7-10 \\
7-9 \\
2-4\end{array}$ & $\begin{array}{c}\text { šir } \\
\text { šir } \\
\text { sre } \\
\text { prealp } \\
\text { šir } \\
\text { euras } \\
\text { adv } \\
\text { euras } \\
\text { adv } \\
\text { euras } \\
\text { euras }\end{array}$ & $\begin{array}{l}+ \\
+\end{array}$ & 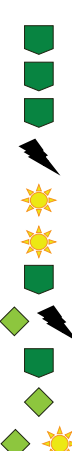 \\
\hline
\end{tabular}


I. Ljubičić i sur.: Samoniklo ljekovito, aromatično i medonosno bilje livada jugoistočnog dijela Samoborskog gorja

\begin{tabular}{|c|c|c|c|c|c|c|c|}
\hline 17 & $\begin{array}{l}\text { BORAGINACEAE } \\
\text { Symphytum officinale L. }\end{array}$ & $\mathrm{H}$ & z.traj & $4-8$ & eur & + & \\
\hline 18 & $\begin{array}{l}\text { BRASSICACEAE } \\
\text { Capsella bursa-pastoris (L.) } \\
\text { Medik. }\end{array}$ & $\mathrm{T}$ & $\mathrm{j}$ & $3-10$ & šir & & \\
\hline 19 & $\begin{array}{l}\text { CARYOPHYLLACEAE } \\
\text { Stellaria media (L.) Vill. }\end{array}$ & $\mathrm{T}$ & $\mathrm{j}$ & $3-10$ & šir & + & \\
\hline $\begin{array}{l}20 \\
21\end{array}$ & $\begin{array}{l}\text { CICHORIACEAE } \\
\text { Cichorium intybus L. } \\
\text { Taraxacum officinale Web. }\end{array}$ & $\begin{array}{l}\mathrm{H} \\
\mathrm{H}\end{array}$ & $\begin{array}{l}\text { z.traj } \\
\text { z.traj }\end{array}$ & $\begin{array}{l}6-9 \\
3-9\end{array}$ & $\begin{array}{c}\text { euras } \\
\text { šir }\end{array}$ & $\begin{array}{l}+ \\
+\end{array}$ & \\
\hline 22 & $\begin{array}{l}\text { CLUSIACEAE } \\
\text { Hypericum perforatum } \mathrm{L} \text {. }\end{array}$ & $\mathrm{H}$ & z.traj & $6-9$ & euras & + & \\
\hline $\begin{array}{l}23 \\
24\end{array}$ & $\begin{array}{l}\text { CONVOLVULACEAE } \\
\text { Calystegia sepium (L.) R.Br. } \\
\text { Convolvulus arvensis L. }\end{array}$ & $\begin{array}{l}\mathrm{H} \\
\mathrm{H}\end{array}$ & $\begin{array}{l}\text { z.traj } \\
\text { z.traj }\end{array}$ & $\begin{array}{l}6-9 \\
5-9\end{array}$ & $\begin{array}{l}\text { šir } \\
\text { šir }\end{array}$ & + & \\
\hline 25 & $\begin{array}{l}\text { DIPSACACEAE } \\
\text { Knautia arvensis (L.) Coult. }\end{array}$ & $\mathrm{H}$ & z.traj & $5-9$ & euras & + & \\
\hline 26 & $\begin{array}{l}\text { EUPHORBIACEAE } \\
\text { Euphorbia cyparissias L. }\end{array}$ & $\mathrm{H}$ & z.traj & $4-7$ & eur & & \\
\hline $\begin{array}{l}27 \\
28 \\
29 \\
30 \\
31 \\
32 \\
33 \\
34\end{array}$ & $\begin{array}{l}\text { FABACEAE } \\
\text { Anthyllis vulneraria } \mathrm{L} . \\
\text { Coronilla varia } \mathrm{L} . \\
\text { Medicago sativa } \mathrm{L} . \\
\text { Melilotus albus } \text { Medik. } \\
\text { Melilotus officinalis (L.) Lam. } \\
\text { Ononis spinosa } \mathrm{L} . \\
\text { Trifolium pratense } \mathrm{L} . \\
\text { Trifolium repens } \mathrm{L} .\end{array}$ & $\begin{array}{l}\mathrm{H} \\
\mathrm{H} \\
\mathrm{H} \\
\mathrm{H} \\
\mathrm{H} \\
\mathrm{H} \\
\mathrm{H} \\
\mathrm{H}\end{array}$ & $\begin{array}{l}\text { z.traj } \\
\text { z.traj } \\
\text { z.traj } \\
\text { d } \\
\text { d } \\
\text { z.traj } \\
\text { z.traj } \\
\text { z.traj }\end{array}$ & $\begin{array}{c}5-9 \\
5-9 \\
7-10 \\
6-9 \\
6-9 \\
6-9 \\
5-9 \\
5-10\end{array}$ & $\begin{array}{l}\text { eur } \\
\text { eur } \\
\text { euras } \\
\text { euras } \\
\text { euras } \\
\text { eur } \\
\text { euras } \\
\text { šir }\end{array}$ & $\begin{array}{l}+ \\
+ \\
+ \\
+ \\
+ \\
+ \\
+ \\
+\end{array}$ & \\
\hline $\begin{array}{l}35 \\
36 \\
37 \\
38 \\
39 \\
40\end{array}$ & $\begin{array}{l}\text { LAMIACEAE } \\
\text { Ajuga reptans } \mathrm{L} \text {. } \\
\text { Betonica officinalis } \mathrm{L} . \\
\text { Mentha longifolia }(\mathrm{L} .) \text { Huds. } \\
\text { Prunella vulgaris } \mathrm{L} . \\
\text { Salvia pratensis } \mathrm{L} . \\
\text { Thymus serpyllum } \mathrm{L} .\end{array}$ & $\begin{array}{r}\mathrm{H} \\
\mathrm{H} \\
\mathrm{H} \\
\mathrm{H} \\
\mathrm{H} \\
\mathrm{Ch}\end{array}$ & $\begin{array}{l}\text { z.traj } \\
\text { z.traj } \\
\text { z.traj } \\
\text { z.traj } \\
\text { z.traj } \\
\text { z.traj }\end{array}$ & $\begin{array}{l}4-8 \\
6-7 \\
6-9 \\
5-9 \\
5-8 \\
5-9\end{array}$ & $\begin{array}{c}\text { euras } \\
\text { eur } \\
\text { šir } \\
\text { šir } \\
\text { submed } \\
\text { eur }\end{array}$ & $\begin{array}{l}+ \\
+ \\
+ \\
+ \\
+ \\
+\end{array}$ & \\
\hline $\begin{array}{l}41 \\
42\end{array}$ & $\begin{array}{l}\text { PLANTAGINACEAE } \\
\text { Plantago lanceolata L. } \\
\text { Plantago media } \mathrm{L} .\end{array}$ & $\begin{array}{l}\mathrm{H} \\
\mathrm{H}\end{array}$ & $\begin{array}{l}\text { z.traj } \\
\text { z.traj }\end{array}$ & $\begin{array}{l}5-9 \\
5-9\end{array}$ & $\begin{array}{l}\text { šir } \\
\text { euras }\end{array}$ & $\begin{array}{l}+ \\
+\end{array}$ & \\
\hline 43 & $\begin{array}{l}\text { POL YGONACEAE } \\
\text { Rumex acetosa L. }\end{array}$ & $\mathrm{H}$ & z.traj & $5-8$ & šir & & U \\
\hline 44 & $\begin{array}{l}\text { PRIMULACEAE } \\
\text { Primula vulgaris Huds. }\end{array}$ & $\mathrm{H}$ & z.traj & $3-4$ & jue & + & 0 \\
\hline
\end{tabular}


I. Ljubičić i sur.: Samoniklo ljekovito, aromatično i medonosno bilje livada jugoistočnog dijela Samoborskog gorja

\begin{tabular}{|c|c|c|c|c|c|c|c|}
\hline $\begin{array}{l}45 \\
46 \\
\end{array}$ & $\begin{array}{l}\boldsymbol{R A N U N C U L A C E A E} \\
\text { Ranunculus acris L. } \\
\text { Ranunculus bulbosus L. }\end{array}$ & $\begin{array}{l}\mathrm{H} \\
\mathrm{G}\end{array}$ & $\begin{array}{l}\text { z.traj } \\
\text { z.traj }\end{array}$ & $\begin{array}{l}5-9 \\
4-7 \\
\end{array}$ & $\begin{array}{c}\text { šir } \\
\text { euras }\end{array}$ & + & \\
\hline 47 & $\begin{array}{l}\boldsymbol{R O S A C E A E} \\
\text { Agrimonia eupatoria } \mathrm{L} .\end{array}$ & $\mathrm{H}$ & z.traj & $6-9$ & circ & & \\
\hline 48 & Filipendula vulgaris Moench & $\mathrm{H}$ & z.traj & $5-7$ & euras & & $x_{0}^{4}$ \\
\hline 49 & Fragaria vesca $\mathrm{L}$ & $\mathrm{H}$ & z.traj & $5-7$ & euras & + & $\diamond$ \\
\hline 50 & Potentilla erecta (L.) Raeuschel & $\mathrm{H}$ & z.traj & $5-8$ & euras & & 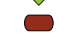 \\
\hline 51 & Potentilla micrantha Ram. & $\mathrm{H}$ & z.traj & $3-5$ & jue & & 0 \\
\hline 52 & Potentilla reptans $\mathrm{L}$. & $\mathrm{H}$ & z.traj & $5-8$ & šir & + & 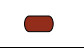 \\
\hline $\begin{array}{l}53 \\
54\end{array}$ & $\begin{array}{l}\boldsymbol{R U B I} \boldsymbol{A C E A E} \\
\text { Galium mollugo L. }\end{array}$ & $\begin{array}{l}\mathrm{H} \\
\mathrm{H}\end{array}$ & z.traj & $\begin{array}{l}5-9 \\
5-9\end{array}$ & $\underset{\text { euras }}{\text { euri }}$ & + & \\
\hline 54 & Galium verum $\mathrm{L}$. & $\mathrm{H}$ & z.traj & $5-9$ & šir & + & \\
\hline 55 & $\begin{array}{l}\text { SCROPHULARIACEAE } \\
\text { Euphrasia rostkoviana Hayne }\end{array}$ & $\mathrm{T}$ & $\mathrm{j}$ & $7-9$ & eur & + & \\
\hline 56 & $\begin{array}{l}\text { URTICACEAE } \\
\text { Urtica dioica } \mathrm{L} \text {. }\end{array}$ & $\mathrm{H}$ & z.traj & $6-9$ & šir & & \\
\hline 57 & $\begin{array}{l}\text { SPERMATOPHYTA } \\
\text { LILIOPSIDA } \\
\text { AMARYLLIDACEAE } \\
\text { Galanthus nivalis L. } \\
\end{array}$ & $\mathrm{G}$ & z.traj & $1-4$ & submed & + & \\
\hline 58 & $\begin{array}{l}\text { LILIACEAE } \\
\text { Ornithogalum umbellatum L. }\end{array}$ & $\mathrm{G}$ & z.traj & 4-6 & eur & & \\
\hline 59 & $\begin{array}{l}\text { ORCHIDACEAE } \\
\text { Orchis morio L. }\end{array}$ & G & z.traj & $4-6$ & euras & & 萧 \\
\hline
\end{tabular}

Taksonomskom analizom 59 ljekovitih i aromatičnih vrsta raspoređeno je unutar 25 porodica (Tablica 1). Jedna porodica (s jednom vrstom) pripada odjeljku papratnjača (Pteridophyta), dok ostale 24 porodice (58 vrsta) pripadaju odjeljku sjemenjače (Spermatophyta). Razredu Magnoliopsida (dvosupnice) pripada 21 porodica (55 vrsta), a tri (svaka sa po jednom vrstom) razredu Liliopsida (jednosupnice) (Tablica 1). Prema brojnosti vrsta prednjače sljedeće porodice: Asteraceae (11), Fabaceae (8), Lamiaceae (6) i Rosaceae (6) (Slika 2). Čak 15 porodica zastupljeno je samo s jednom vrstom. Ovakav raspored ukazuje na veliku raznolikost, ne samo ljekovitih i aromatičnih biljnih vrsta, već i cjelokupne livadne flore istraživanog područja (Slika 2). Što se tiče životnog oblika ustanovljeno je najviše hemikriptofita (46 biljnih vrsta) što čini udio od $77,97 \%$ (Slika 4). S obzirom na trajanje života dominantne su zeljaste trajnice, njih 49 tj. 83,05\% (Slika 5). Najveći broj biljnih vrsta pripada euroazijskom flornom elementu (22 biljne vrste - 37,29\%), a potom slijede biljne vrste široke rasprostranjenosti (broj vrsta - 30,51\%) i biljke europskog flornog elementa 
I. Ljubičić i sur.: Samoniklo ljekovito, aromatično i medonosno bilje livada jugoistočnog dijela Samoborskog gorja

(broj vrsta - 15,25\% (Slika 3). Dio biljke koji se najčešće sakuplja je zelen (nadzemni dio biljke), a prikuplja se kod $62,71 \%$ vrsta. Listovi se sakupljaju kod $18,65 \%$, a korijen kod $16,95 \%$ biljnih vrsta. Ostali biljni dijelovi manje se sakupljaju (Slika 6).

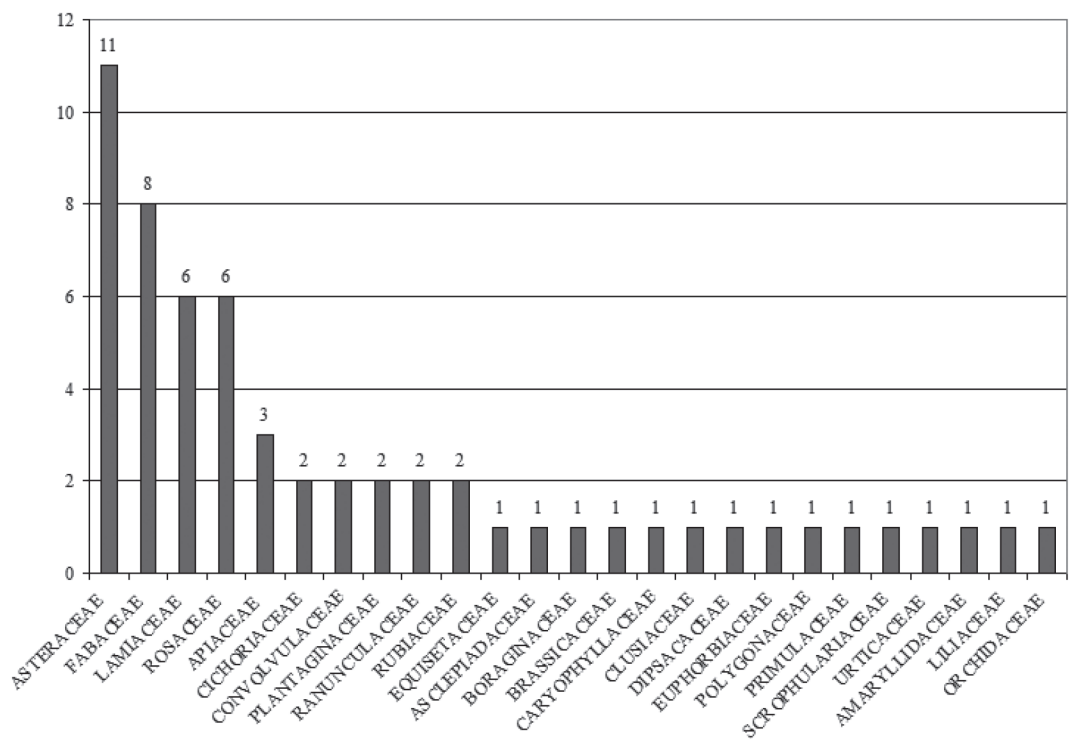

Slika 2. Zastupljenost ljekovitih i aromatičnih vrsta prema porodicama

Picture 2 Representation of medicinal and aromatic species by families

Fitogeografskom analizom ustanovljeno je da su prikupljene ljekovite i aromatične vrste livada jugoistočnog dijela Samoborskog gorja raspoređene unutar devet flornih elemenata. Najviše vrsta pripada euroazijskom flornom elementu (22 biljne vrste), zatim slijede biljke široke rasprostranjenosti (18 biljnih vrsta), te biljne vrste koje pripadaju europskom flornom elementu (devet biljnih vrsta). Kao što je već uočeno u prijašnjim istraživanjima na ovom području (Dujmović Purgar i Hulina, 2006.), ovako velik broj flornih elemenata (devet) ukazuje na prijelazni karakter istraživanog područja u fitogeografskom smislu (Slika 3). 
I. Ljubičić i sur.: Samoniklo ljekovito, aromatično i medonosno bilje livada jugoistočnog dijela Samoborskog gorja

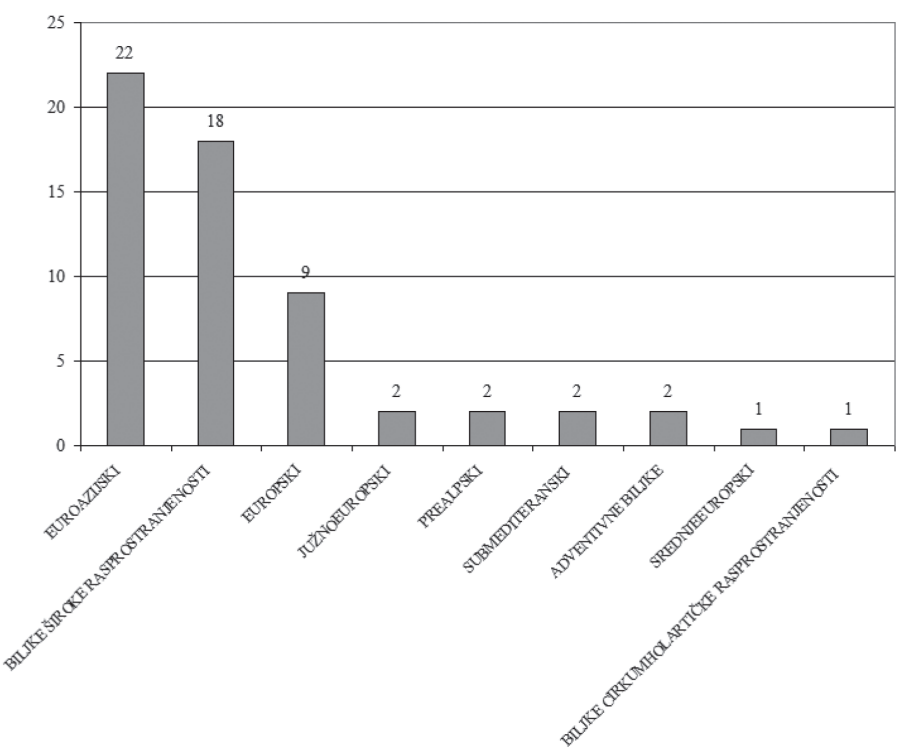

Slika 3. Zastupljenost ljekovitih i aromatičnih vrsta prema flornom elementu

Picture 3 Representation of medicinal and aromatic species according to the floral element

Promatrajući raspodjelu prikupljenih vrsta prema životnom obliku uočava se dominacija Hemicryptophyta (46 vrsta), dok je skupina Geophyta zastupljena sa sedam, Therophyta s pet, a Chamaephyta s jednom vrstom (Slika 4).
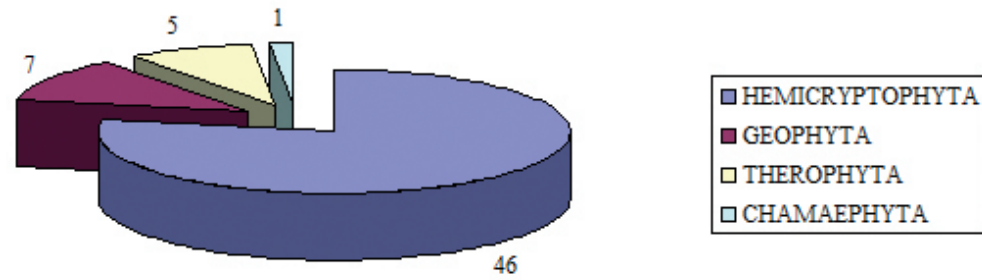

Slika 4. Zastupljenost životnih oblika ljekovitih $i$ aromatičnih vrsta

Picture 4 Representation of life forms of medicinal and aromatic species 
I. Ljubičić i sur.: Samoniklo ljekovito, aromatično i medonosno bilje livada jugoistočnog dijela Samoborskog gorja

Što se tiče dužine trajanja života prevladavaju zeljaste trajnice (49 vrsta) dok po pet vrsta pripada jednogodišnjim i dvogodišnjim biljkama (Slika 5). Ovakvi rezultati su i očekivani jer su livade kao agroekosustavi podvrgnute znatno manjim antropogenim utjecajima nego primjerice oranice (Dujmović Purgar i Hulina, 2006.).

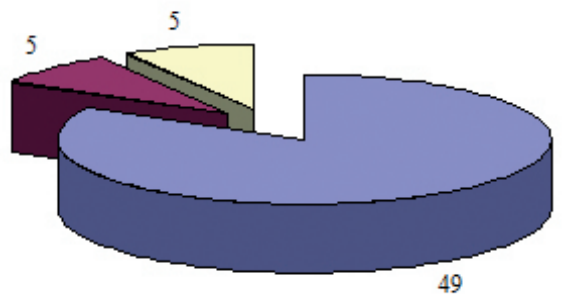

口ZELJASTE TRAJNICE

$\square$ JEDNOGODIŠNJE

口DVOGODIŠNJE

Slika 5. Zastupljenost ljekovitih i aromatičnih vrsta prema dužini trajanja života

Picture 5 Representation of medicinal and aromatic species over the life cycle

Osim što se odlikuju ljekovitim i aromatičnim svojstvima, neke biljne vrste mogu poslužiti i za pčelinju pašu. Na istraživanom području zabilježena je 41 vrsta medonosnog bilja.

Da bi određenu ljekovitu ili aromatičnu biljku mogli pravilno i učinkovito primijeniti u medicinske svrhe ili za dobivanje začina, potrebno je znati koji dio biljke treba sakupljati, te u kojem obliku droge se ta vrsta koristi. Analizom prikupljenih biljnih vrsta livada jugoistočnog dijela Samoborskog gorja utvrđeno je da se najčešće sakuplja nadzemni dio biljke bez odrvenjelih dijelova - zelen 37 biljnih vrsta i list kod 11 biljnih vrsta, a ostali biljni organi se sakupljaju kod manjeg broja vrsta (Slika 6). Treba napomenuti da se kod nekih biljaka sakuplja više dijelova kao na primjer kod vodopije (Cichorium intybus L.) gdje se u doba cvatnje ubire zelen, a u jesen iskopava korijen (Tablica 1). 
I. Ljubičić i sur.: Samoniklo ljekovito, aromatično i medonosno bilje livada jugoistočnog dijela Samoborskog gorja

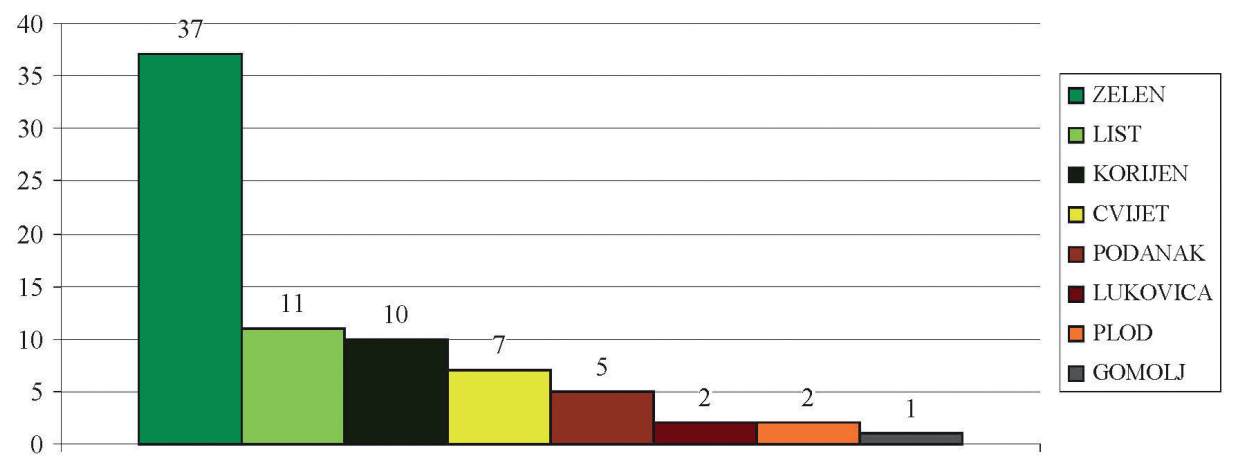

Slika 6. Prikaz broja vrsta kod kojih se određeni organ sabire za dobivanje droge Picture 6 Representation of number of species in which a part of the plant is used for drug production

Posebna pažnja posvećena je ljekovitim i aromatičnim vrstama koje su opisane u Hrvatskoj farmakopeji i čije se droge smatraju oficijelnim. Na istraživanom području prikupljeno je 12 takvih biljnih vrsta (13,64\% od ukupno prikupljenih, a $20,34 \%$ od izdvojenih ljekovitih i aromatičnih vrsta), a to su sljedeće: Achillea millefolium L., Agrimonia eupatoria L., Carum carvi L., Equisetum arvense L., Hypericum perforatum L., Melilotus officinalis (L.) Lam., Ononis spinosa L., Plantago lanceolata L., Potentilla erecta (L.) Raeuschel, Solidago canadensis L., Thymus serpyllum L. i Urtica dioica L. Ove biljne vrste sadrže farmakološki djelatne sastojke (alkaloide, glikozide, saponine, treslovine, eterična ulja, smole $\mathrm{i}$ dr.) pa su prikladne u obliku ljekovitih droga za primjenu u medicini, prvenstveno za izradu lijekova (Grdinić i Kremer, 2009.).

\section{ZAKLJUČAK}

Terenskim istraživanjem provedenim na livadama jugoistočnog dijela Samoborskog gorja u vegetacijskoj sezoni 2010. i 2011. godine prikupljeno je ukupno 88 svojti. Biljne vrste raspoređene su unutar 25 porodica od kojih prema brojnosti prednjače Asteraceae, Fabaceae, Lamiaceae i Rosaceae. Najzastupljeniji florni element je euroazijski s 22 biljne vrste. Prema životnom obliku dominira skupina hemikriptofita, a prema trajanju života zeljaste trajnice. 
I. Ljubičić i sur.: Samoniklo ljekovito, aromatično i medonosno bilje livada jugoistočnog dijela Samoborskog gorja

Analizom biljnog materijala utvrđeno je da od ukupnog broja prikupljenih biljnih vrsta broj vrsta (67\%) pripada skupini ljekovitog i aromatičnog bilja. Medonosna je 41 vrsta. Dakle, može se zaključiti da su livade jugoistočnog dijela Samoborskog gorja bogate ljekovitim, aromatičnim i medonosnim biljem.

Dio biljke koji se najčešće sakuplja (odnosno droga koja se najviše koristi) je zelen - nadzemni dio biljke bez odrvenjelih dijelova, a sakupljamo ga kod $62,71 \%$ vrsta. Kod nekih vrsta sabire se nekoliko dijelova biljke (dva, ponekad i tri različita dijela) od kojih se spravljaju biljne droge.

Biljne droge kod 20,34\% ustanovljenih vrsta, smatraju se oficijelnima i uvrštene su u Hrvatsku farmakopeju (2007.).

\section{LITERATURA}

1. Bonnier, G. (1962.): Flore comléete illustrée en Couleurs de France, Suisse et Belgique, 1-12. Neuchatel et Bruxelles, Paris.

2. Domac, R. (1994.): Flora Hrvatske: priručnik za određivanje bilja. Školska knjiga, Zagreb.

3. Dujmović, I. (2007.): Fizičko-geografske značajke Samoborskog gorja i Plješivičkog prigorja. Meridijani, Samobor.

4. Dujmović Purgar, D., Hulina, N. (2006.): Korovna flora livada Plešivičkog prigorja. Agronomski glasnik 6, 443-457.

5. Forenbacher, S. (1995.): Žumberak - kalendar flore Žumberačke gore. Školska knjiga, Zagreb.

6. Galle Toplak, K. (2001.): Hrvatsko ljekovito bilje. Mozaik knjiga, Zagreb.

7. Gelenčir, J., Gelenčir, J. (1991.): Atlas ljekovitog bilja. Prosvjeta, Zagreb.

8. Garcke, A. (1972.): Illustrierte Flora Deutschland und angrenzende gebiete, geffasskryptogamen und Blutenpflanzen. Berlin - Hamburg.

9. Grdinić, V., Kremer, D. (2009.): Ljekovito bilje i ljekovite droge: farmakoterapijski, botanički i farmaceutski podaci. Hrvatska ljekarnička komora, Zagreb.

10. Hegi, G. (1906 - 1931.): Illustrierte Flora von Mitteleuropa, 1-7. J. F. Lehmans Verlag, München.

11. Hulina, N. (1989.): Prikaz i analiza flore u području Turopolja. Acta Bot. Croat. 48, 141-160.

12. Hulina, N. (1991.): Segetalna i ruderalna flora u području Turopolja. Frag. Herbol. 20 (1-2), 5-9. 
I. Ljubičić i sur.: Samoniklo ljekovito, aromatično i medonosno bilje livada jugoistočnog dijela Samoborskog gorja

13. Javorka, S., Csapody, V. (1934.): A magyar flóra Képekben (Iconographia Florae Hungaricae). "Studium", Budapest.

14. Knežević, M. (2006.): Atlas korovne, ruderalne i travnjačke flore. Sveučilište u Osijeku Poljoprivredni fakultet, Osijek.

15. Kovačević, J. (1976.): Korovi u poljoprivredi. Nakladni zavod Znanje, Zagreb.

16. Kovačević, P., Kalinić, M., Pavlić, V., Bogunović, M. (1971.): Tla Gornje Posavine. Institut za pedologiju i tehnologiju tla Poljoprivrednog fakulteta, Zagreb.

17. Kuštrak, D. (2005.): Farmakognozija - fitofarmacija. Golden marketing tehnička knjiga, Zagreb.

18. Nikolić, T. ed. (2017.): Flora croatica baza podataka. On-Line (http://hirc.botanic.hr/fcd). Botanički zavod, Prirodoslovno-matematički fakultet, Sveučilište u Zagrebu.

19. Penzar, I., Penzar, B. (1989.): Agroklimatologija. Školska knjiga, Zagreb.

20. Šegulja, N. (1977.): Analiza flore Vukomeričkih gorica. Biosistematika 3 (1), 45-59.

21. Šimić, F. (1980.): Naše medonosno bilje. Znanje, Zagreb.

22. Trinajstić, I. (2008.): Biljne zajednice Republike Hrvatske. Akademija šumarskih znanosti, Zagreb.

23. Tutin, T. G., Heywood, V. H. (eds.) (1964 - 1980., 1993.): Flora Europaea, 15. University Press, Cambridge.

24. Vrbek, M. (2000.): Ruderalna i korovna flora Žumberka. Magistarski rad, Sveučilište u Zagrebu.

\section{Adresa autora - Author's address:}

Doc. dr. sc. Ivica Ljubičić, e-mail: iljubicic@agr.hr

Filip Vugrinčić

Izv. Prof. dr.sc. Dubravka Dujmović Purgar

Sveučilište u Zagrebu Agronomski fakultet

Zavod za poljoprivrednu botaniku

Svetošimunska cesta 25

10000 Zagreb
Primljeno - received:

25.08.2017. 